\title{
Zum neuen Jahr: \\ Machen Sie sich das Leben einfacher!
}

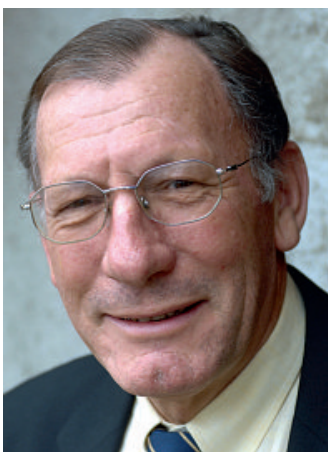

Jean Martin
Vor den Feiertagen war ich drei Wochen in Amerika, zur Tagung des internationalen Bioethik-Ausschusses der UNESCO in Mexiko und auf Besuch bei einem unserer Kinder in der Nähe von New York - wo ich nicht nur die Freuden des Grossvaterdaseins geniessen durfte, sondern auch zum Lesen kam. So habe ich wieder einmal das hervorragende Buch Three men in a boat von Jerome K. Jerome aus dem Jahr 1889 genossen. Witzig, voll besten britischen Humors, allerdings auch mit frauenfeindlichen Bemerkungen, die heute zu Recht als «nicht korrekt» eingestuft würden.

Aus der Ecke der Lebensratgeber (auch in meinem Alter noch nützlich!) las ich ein Büchlein darüber, wie man sein Leben vereinfacht [1]. Es beginnt mit einem Zitat von Jerome K. Jerome: «Lasst euer Lebensschifflein leicht dahinschweben, nur mit dem Nötigsten beschwert! Ein heimliches Nest mit seinen stillen Freuden, ein oder zwei Freunde, die dieses Namens wert; jemand, den ihr liebt, und jemand, der euch liebt! Eine Katze, ein Hund, eine Pfeife oder zwei ...» Elaine St. James, die als ehemaliger «yuppie whose life was consumed and consuming» beschrieben wird (eine ehrgeizige, getriebene und konsumorientierte junge Frau der 1980er Jahre, mit dem Lebensmotto more is better), ist zu einem Leben mit erheblich mehr Einfachheit und weniger Konsum gelangt und hat dazu 100 Ratschläge ausgearbeitet, zu Themen von Haushaltsführung bis Lebensstil, über Finanzen, Arbeit und einige special issues for women.

Sie betont, dass es für sie und ihren Mann, der ihre Einstellung teilt, nicht um eine feste Doktrin geht, sondern darum, Unruhe und Überflüssiges zu reduzieren ohne dabei auf einen gewissen Komfort zu verzichten. Darum, die Zwänge und die Komplexität ihres früheren Lebens zu verringern -, ohne dabei zu vergessen, dass des einen Einfachheit des anderen Komplexität sein kann. So lautet einer ihrer Tipps, erheblich weniger Zeit und Energie in alles zu stecken, was mit Feiertagen wie Weihnachten und Neujahr zu tun hat: keine Weihnachtskarten mehr, viel einfachere Geschenke und Feiern. Das kann natürlich in manchen Kontexten schlecht ankommen und die Dinge noch verkomplizieren - und Familienfeste sind schliesslich nicht immer schrecklich. Immer wieder greift die Autorin die allgegenwärtige Werbung scharf an, die einen zwanghaften und amoralischen Druck auf die Öffentlichkeit ausübt (vgl. [2]) und die Konsumenten dazu erzieht, «ständig unzufrieden, unersättlich, verängstigt und gelangweilt» zu sein.

Der planlosen Anhäufung in unserem Leben ein Ende setzen. Entrümpeln. Faustregel hierzu: Wenn Sie etwas seit einem Jahr nicht benutzt haben, werfen
Sie es weg. (Tremendously liberating, sagt die Autorin.) Und der Vorschlag zur praktischen Umsetzung: Dinge, die man selten oder nie benutze, in einen Karton pakken und mit einem Datum in zwei oder drei Jahren beschriften. Wenn dieser Tag gekommen ist, und Sie den Inhalt des Kartons nicht vermisst haben, werfen Sie ihn unbesehen weg. Sich ebenso vor wichtigen Anschaffungen Bedenkzeit nehmen.

Nicht länger der Sklave seiner ausgefeilten Zeitmanagementwerkzeuge sein. (Gefährlich wird es, wenn der Terminplaner vom unterstützenden Hilfsmittel zum kontrollierenden Diktator wird.) Nah am Arbeitsplatz wohnen. Wenn irgend möglich, sein Hobby zur Erwerbsarbeit machen. Busy work vermeiden, also sich nicht um der Beschäftigung selbst willen beschäftigen, ohne erkennbares Ergebnis. Immer nur eine Sache zurzeit tun. Sorgfältig auswählen, welche Anrufe man annimmt (und als ersten Schritt dazu den Anrufbeantworter in Betrieb nehmen). Alle Abonnements und Mitgliedschaften beenden, die man nicht wirklich nutzt.

Einen Urlaub zu Hause verbringen - das kann grossen Spass machen. Einen Abend pro Woche um neun Uhr ins Bett gehen, einen Tag im Monat in Abgeschiedenheit verbringen.

Lachen lernen, meditieren lernen. Die Angst abschalten, «was wohl die anderen davon halten»nicht das sein, was andere gern von Ihnen hätten, sondern nach dem Grundsatz leben, dass Sie die einzige Person sind, deren Meinung zählt. Wenn etwas trotz aller Anstrengungen nicht funktioniert: Loslassen, statt sich festzubeissen - «Es geht nun einmal kein eckiger Balken in ein rundes Loch.»

Und ebenso wichtig: Aufhören, andere Menschen ändern zu wollen. «Was sich alle Menschen wünschen, auch Partner und Kinder, ist ein wohlwollender $\mathrm{Zu}$ hörer. Ändern werden sie sich dann, wenn sie dazu bereit sind.» Lernen, nein zu sagen (das müssen viele von uns!): «Vielen Dank für das Angebot, aber die Antwort ist nein.» Wem solche Direktheit nicht liegt, soll sich eine Reihe vielseitig verwendbarer Entschuldigungen zurechtlegen. Und schliesslich: Frustrierende Erlebnisse und Misserfolge zu den Akten legen können, sich nicht mit der Frage belasten, wie alles hätte werden können, wenn man selbst oder die anderen anders gehandelt hätten.

Ein schönes Programm, nicht wahr? Mit meinen besten Wünschen,

Dr. med. Jean Martin, Mitglied der Redaktion und der nationalen Ethikkommission 